\title{
Communication \\ Expression of Kisspeptin 1 in the Brain of the Adult Sea Lamprey Petromyzon marinus
}

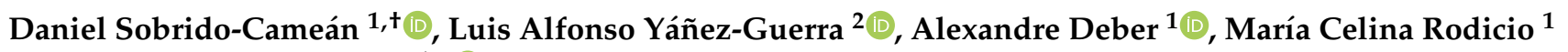 \\ and Antón Barreiro-Iglesias 1,*(i) \\ 1 Department of Functional Biology, CIBUS, Faculty of Biology, Universidade de Santiago de Compostela, \\ 15782 Santiago de Compostela, Spain; ds918@cam.ac.uk (D.S.-C.); xandredl@hotmail.com (A.D.); \\ mcelina.rodicio@gmail.com (M.C.R.) \\ 2 Living Systems Institute, University of Exeter, Exeter EX4 4QD, UK; L.Yanez-Guerra@exeter.ac.uk \\ * Correspondence: anton.barreiro@usc.es \\ + Present address: Department of Zoology, University of Cambridge, Cambridge CB2 3EJ, UK.
}

check for updates

Citation: Sobrido-Cameán, D.

Yáñez-Guerra, L.A.; Deber, A.; Rodicio, M.C.; Barreiro-Iglesias, A. Expression of Kisspeptin 1 in the Brain of the Adult Sea Lamprey Petromyzon marinus. Life 2021, 11, 1174. https://doi.org/10.3390/life11111174

Academic Editor: Christina Piperi

Received: 5 October 2021

Accepted: 1 November 2021

Published: 3 November 2021

Publisher's Note: MDPI stays neutral with regard to jurisdictional claims in published maps and institutional affiliations.

Copyright: (c) 2021 by the authors. Licensee MDPI, Basel, Switzerland. This article is an open access article distributed under the terms and conditions of the Creative Commons Attribution (CC BY) license (https:/ / creativecommons.org/licenses/by/ $4.0 /)$.

\begin{abstract}
Kisspeptin peptides play major roles in the regulation of reproduction and puberty onset in mammals. While most mammals only have one kisspeptin gene, other jawed vertebrates present two or three genes. Recent data also revealed the presence of two genes in lampreys (jawless vertebrates). However, apart from gene sequence data, there is almost no information on the kisspeptinergic system of lampreys. Here, we report phylogenetic and cluster-based analyses showing that the duplication of the ancestral kisspeptin gene occurred before the separation of jawless and jawed vertebrates. We also studied the expression of the kisspeptin transcripts in the brain of post-metamorphic juveniles and upstream migrating adult sea lampreys. Our in situ hybridization results revealed expression of kisspeptin 1 in hypothalamic neurons, which indicates that the hypothalamic expression of kisspeptins is an ancestral character in vertebrates. We also observed the presence of kisspeptin 1 expressing neurons in the paratubercular (posterior tubercle) nucleus of the diencephalon. This is the first description of the presence of kisspeptin 1 expressing neurons in this brain region in any vertebrate. We did not detect expression of kisspeptin 2 in the juvenile or adult sea lamprey brain with in situ hybridization. Our data provides an anatomical basis to study the role of kisspeptin 1 in the hypothalamic-pituitary system of lampreys and the contribution of diencephalic kisspeptinergic neurons to different circuits of the lamprey brain.
\end{abstract}

Keywords: kisspeptin; hypothalamus; in situ hybridization; lamprey; reproduction

\section{Introduction}

Kisspeptin (Kiss) neuropeptides are part of the RFamide family [1], and they act by binding G-protein coupled receptors that are named GPR54 or KissR [2]. Functional Kiss genes are present in most vertebrates (apart from birds, which only present a Kiss pseudogene [3]) and vertebrate Kiss genes are derived from an ancestral Kiss gene that during evolution underwent several duplications followed by gene losses [4]. Actinopterygians have 2 Kiss genes (Kiss1 and Kiss2), amphibians, like Xenopus, have 3 (Kiss $1 a$, Kiss $1 b$ and Kiss2) and most mammals only have the Kiss1 gene [4]. The recent identification of Kiss1 and Kiss2 genes in the sea lamprey suggested that the duplication of the ancestral Kiss gene occurred before the separation of jawless and jawed vertebrates [4,5]. However, the possibility that this is a linage-specific duplication in lampreys should not be excluded and new phylogenetic analyses that include the sea lamprey Kiss precursors and the third Kiss genes from other vertebrates (e.g., Xenopus) are needed to differentiate between these two scenarios. Mature Kiss peptides play a major role in the regulation of reproduction in mammals, with Kiss 1 expressing hypothalamic neurons playing an essential role in the regulation of puberty onset and the control of gonadotropin releasing hormone $(\mathrm{GnRH})$ and gonadotropin secretion [6]. 
Lampreys occupy an interesting phylogenetic position to infer ancestral characters fixed prior to the divergence of jawless and jawed vertebrates or to identify lineage specific diversifications. Sea lampreys, Petromyzon marinus L, have a complex life cycle with a filter-feeding larval period lasting several years in the river followed by a transformation into young adults (juveniles) that migrate to the sea before returning to the river to breed and die. Work in the last decades has provided interesting genetic, neuroanatomical, and functional data on the hypothalamic-pituitary system of lampreys and on many of the hormonal/neuropeptidergic (e.g., GnRHs) systems controlling the life cycle and reproduction of lampreys (for a review see [7]). However, the kisspeptinergic system has not yet been thoroughly studied in lampreys and there is no information on the expression or role of kisspeptins in these animals. Only one study has reported the inhibitory effect of lamprey Kiss 1 mature peptides on the expression of the luteinizing hormone 8 subunit in primary cultures of eel pituitary cells [8]. The recent identification of Kiss genes in the sea lamprey genome ([3]; see above) provides a basis to study their expression and the organization of the kisspeptinergic system in lampreys, which will increase our knowledge on the evolution of this system and the physiological control of reproduction in vertebrates.

Here, we performed phylogenetic and cluster-based (CLANS) analyses of the vertebrate Kiss precursors and aimed to study the expression of the 2 Kiss transcripts in the brain of sea lampreys, both in young post-metamorphic juveniles and in upstream migrating adults. Our in situ hybridization data revealed the presence of hypothalamic neurons expressing Kiss1. This indicates that hypothalamic Kiss expression is an ancestral character for all vertebrates and that Kiss1 might also play a role in the control of GnRH release in lampreys. Our anatomical data provides a basis for future functional studies on the kisspeptinergic system in lampreys.

\section{Materials and Methods}

2.1. Alignment of the Kiss1 and Kiss2 Sea Lamprey Precursor Sequences with Kiss Precursor Sequences from other Chordates and Phylogenetic Analyses

The Petromyzon marinus Kiss cDNA sequences were identified using the human Kiss precursor as a query (GenBank accession number: NP_002247.3) and performing TBLASTn against the P. marinus TSA database. The sea lamprey Kiss1 and Kiss2 cDNA sequences were translated to the corresponding amino acid sequence using the ExPASy website translate tool (https: / / web.expasy.org/translate/, accessed on 4 October 2021). To investigate the relationship of the sea lamprey Kiss1 and Kiss2 precursors to other Kiss precursors, sequences from other species were obtained from GenBank and used to perform a phylogenetic analysis using the maximum-likelihood method (see Supplementary Files S1 and S2 for a list of the precursors). The amino acid sequences of the sea lamprey Kiss precursors were aligned with Kiss precursors from other species using MAFFT (G-INS-I iterative; see Supplementary File S3 for the sequences used for the tree and the accession numbers of the sequences). The alignment was trimmed using TrimAl in the automated option [9]. The tree was constructed using PhyML [10]. The percentage of replicate trees in which the associated taxa clustered together in the approximate Bayesian branch support test (aBayes, 1000 replicates) are shown with stars in Figure 1. The substitution model used was the LG + G4 model. The tree was rooted using figtree v1.4.4 and the tree was exported using this tool. The raw tree data is available as the Supplementary File S4.

Finally, the alignment with no trimming was used to highlight the conserved residues using the software BOXSHADE (www.ch.embnet.org/software/BOX_form.html, accessed on 4 October 2021) with 70\% conservation as the minimum for highlighting. The whole precursor highlighting is available in the Supplementary Files S1 and S2. The regions containing the mature peptide were trimmed and used to show the conservation of the Kiss mature peptides belonging to the Kiss 1 and Kiss 2 clusters of sequences. Finally, the sequences were highlighted in phylum-specific colours: mammals (gray), sauropsids (red), amphibians (orange) lobe-finned fishes (yellow), ray-finned fishes (green), cartilaginous fishes (purple), and agnathans (blue). 


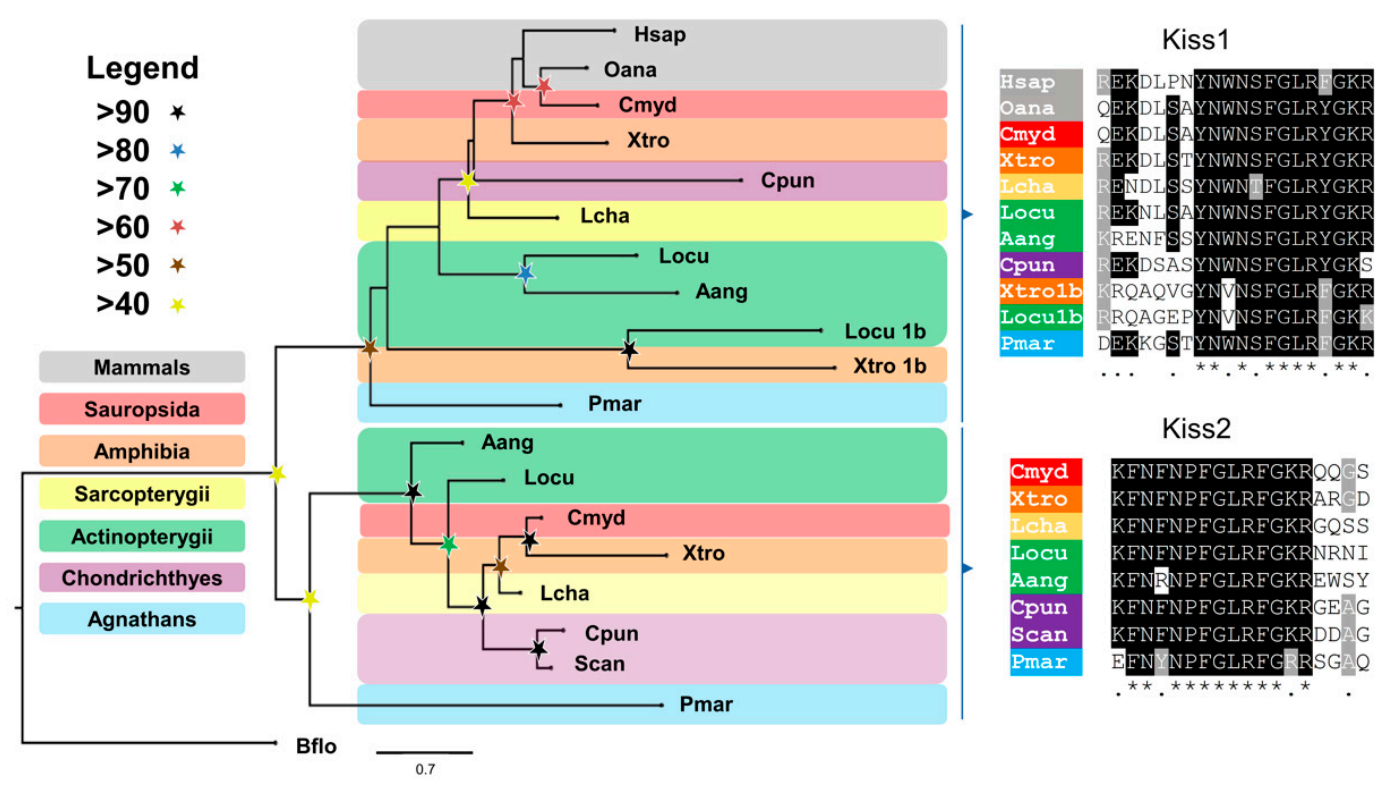

Figure 1. Maximum-likelihood tree and alignment of the C-terminal region of Kiss precursors showing relationships of these precursor proteins from selected chordate species. The percentages of replicate trees in which the associated taxa clustered together in the approximate Bayesian branch support test (aBayes 1000 replicates) are shown with stars as explained in the key. In the right side, alignments of the C-terminal region, including the mature peptides of Kiss 1 and Kiss 2 precursors are shown. The conserved residues are highlighted, with conservation in more than $70 \%$ of sequences shown in black (asterisks indicate a $100 \%$ of conservation in a specific residue) and with conservative substitutions shown in grey. Species names in the tree and alignment are as follows: Hsap (Homo sapiens), Oana (Ornithorhynchus anatinus), Cmyd (Chelonia mydas), Xtro (X. tropicalis), Lcha (Latimeria chalumnae), Locu (Lepisosteus oculatum), Aang (A. anguila), Cpun (Chiloscyllium punctatum), Scan (Scyliorhinus canicula), Pmar (P. marinus).

To further investigate the relationship of the sea lamprey Kiss precursors with other vertebrate precursors we performed a cluster-based analysis (CLANS). Using the same sequences for the phylogeny an all-versus-all analysis was performed using CLANS [11] with the matrix BLOSUM62 as the scoring matrix. Sequences were clustered with an e-value cut-off of $1 \times 10^{-8}$ to identify clusters. The clustering was collapsed to $2 \mathrm{D}$ to enable the generation of the diagram. The clustering analysis is available as Supplementary Figure S1.

\subsection{Animals}

Larvae $(n=8)$, downstream migrating young (post-metamorphic juveniles; $n=3)$ and upstream migrating $(n=3)$ adult sea lampreys, Petromyzon marinus L., were used in this study. Larvae and downstream migrating young adults were collected from the River Ulla (Galicia, Spain) with permission from the Xunta de Galicia. Upstream migrating adults were acquired from local suppliers. Before all experiments, animals were anesthetized with $0.1 \%$ tricaine methanesulfonate (Sigma, St. Louis, MO, USA) in fresh water and killed by decapitation. Information on the sex of juvenile/adult animals was not available since we used a collection of brains already stored in the laboratory. All experiments were approved by the Bioethics Committee at the University of Santiago de Compostela and the Consellería do Medio Rural of the Xunta de Galicia (Ref. 15012/2020/011) and were performed in accordance with European Union and Spanish guidelines on animal care and experimentation.

\subsection{Cloning and Sequencing of the Sea Lamprey Kiss1 and Kiss2 cDNAs}

Total RNA was obtained from the central nervous system (brain and spinal cord) of the larval samples by using the TriPure reagent (Roche, Basel, Switzerland). cDNA synthesis reaction from total RNA was catalysed with Superscript III reverse transcrip- 
tase (Invitrogen, Waltham, MA, USA) using random hexamer primers (Invitrogen). For polymerase chain reaction (PCR) amplification, specific primers (Kiss1: forward: $5^{\prime}-$

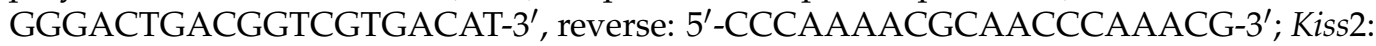
forward: $5^{\prime}$-GGAGGAGATCGTCACCGGG-3' ${ }^{\prime}$, reverse: $5^{\prime}$-GCAGGCCGAAGGGGTTGTA$3^{\prime}$ ) were designed based on the P. marinus L Kiss1 and Kiss2 transcript precursor sequences (GenBank accession numbers KT202350.1 and KT202356.1 [12]). The amplified fragments were cloned into pGEM-T easy vectors (Promega, Madison, WI, USA) and sequenced by GATC Biotech (Cologne, Germany). This confirmed that we cloned a 364 bp cDNA sequence of the sea lamprey Kiss1 and a 209 bp cDNA sequence of the sea lamprey Kiss2.

\subsection{In Situ Hybridization on Tissue Sections}

Templates for riboprobe generation were prepared by PCR amplification of the cloned Kiss1 and Kiss2 cDNA fragments using the primers mentioned above, although in this case the reverse primers included the sequence of the T7 promoter (TAAGCTTTAATACGACTCACTATAGGGAGA). For the generation of sense probes, the sequence of the T7 promoter was included in the forward primers. Digoxigenin (DIG)-labelled riboprobes were synthesized using the amplified fragments as templates and a T7 RNA polymerase (Nzytech, Lisbon, Portugal).

In situ hybridization was performed as previously described for other neuropeptide riboprobes in the sea lamprey [13-15]. Briefly, the brains/rostral spinal cords of young and mature adults were fixed by immersion overnight in $4 \%$ paraformaldehyde in phosphatebuffered saline (PBS) at $4{ }^{\circ} \mathrm{C}$. They were cryoprotected with $30 \%$ sucrose in PBS, embedded in Tissue Tek (Sakura, Torrance, CA, USA), frozen in liquid nitrogen-cooled isopentane, and cut serially on a cryostat (14 $\mu \mathrm{m}$ thickness) in transverse planes. Sections were mounted on Superfrost ${ }^{\circledR}$ Plus glass slides (Menzel, Braunschweig, Germany). The sections were incubated with the DIG-labelled antisense riboprobe $(1 \mu \mathrm{g} / \mathrm{mL})$ at $70{ }^{\circ} \mathrm{C}$ overnight in hybridization mix and treated with RNAse A (Sigma) in the post-hybridization washes. Then the sections were incubated with a sheep anti-DIG antibody conjugated to alkaline phosphatase (1:2000; Roche, Basel, Switzerland) overnight at $4{ }^{\circ} \mathrm{C}$. The colorimetric reaction was conducted using BM Purple (Roche) at $37^{\circ} \mathrm{C}$ until the signal was clearly visible. The sections were mounted using Mowiol ${ }^{\circledR}$ (Sigma). No staining was observed in the sections incubated with the sense probes (Supplementary Figure S2A).

\subsection{Imaging and Figure Preparation}

Photographs of brain sections were taken with an Olympus microscope (AX-70; Provis, Olympus, Tokyo, Japan) equipped with a digital camera (Olympus DP70). Schematics and plates of photomicrographs shown in Figure 1 were generated with Adobe Photoshop CS6 (Adobe, San Jose, CA, USA).

\section{Results}

\subsection{Sequence Analyses}

Based on an alignment of 20 selected Kiss precursor protein sequences from different gnathostome species and the agnathan P. marinus, a phylogenetic reconstruction was performed using the maximum-likelihood method. The tree was rooted using the sequence of a Kiss precursor from Branchiostoma floridae. Most of the species included in the analyses have two Kiss precursors, Kiss1 and Kiss2. The exceptions were Xenopus tropicalis and Lepisosteus oculatus, in which there are three different Kiss precursors (the third one named as Kiss1b). As shown in Figure 1, the phylogenetic reconstruction revealed the presence of only two branches constituting two clusters of Kiss precursors, the Kiss 1 and Kiss 2 clusters. The third precursor identified in X. tropicalis and L. oculatus form part of the Kiss 1 branch of the tree, suggesting that they represent a recent duplication of Kiss 1 in these species. It is important to notice that the node supporting the two main branches of Kiss 1 and Kiss 2 displays a low branch support value ( $>40 \%)$. Thus, to further test this hypothesis, a clusterbased analysis was performed with CLANS. The cluster analysis revealed a similar pattern 
to the one obtained in the phylogenetic analysis, with two main clusters produced by the sequences. One cluster corresponding to the Kiss1 precursors and the other one containing the Kiss 2 sequences. The Kiss $1 \mathrm{~b}$ precursor sequences from L. oculatus and X. tropicalis show connections only to the Kiss 1 cluster.

An alignment of the predicted mature peptides shows that there is a high degree of conservation of the mature peptides in vertebrates. The mature Kiss1-10 peptides (including the duplicated ones from $X$. tropicalis and L. oculatus) have the consensus sequence YNWNSFGLRYG, while the Kiss2-10 peptides have the consensus sequence FNFNPFGLRFG. A comparison of the P. marinus Kiss1 peptide against the consensus sequence shows that there is only 1 mutation in the $\mathrm{C}$-terminal region, with the exchange of the (Y-amide) tyrosine-amide for an (F-amide) phenylalanine-amide (Figure 1). In the case of the Kiss2 peptide, there is one mutation in the $\mathrm{N}$-terminal region, with the exchange of the second (F) phenylalanine for a $(\mathrm{Y})$ tyrosine (Figure 1).

\subsection{Expression of the Kiss1 and Kiss2 Transcripts in the Adult Sea Lamprey Brain}

As indicated in the materials and methods section, we cloned partial sequences of the sea lamprey Kiss 1 and Kiss 2 cDNAs and used them as templates to generate specific riboprobes that were used for in situ hybridization in transverse sections of the sea lamprey brain. We did not detect expression of Kiss 2 transcripts in the brains of post-metamorphic juveniles or upstream migrating adults (Supplementary Figure S2B). In the case of Kiss1, we did not detect any differences in the distribution and location of Kiss1-expressing cells in post-metamorphic juveniles and upstream migrating adults; therefore, Kiss 1 in situ hybridization results are described together for both stages (Figure 2).

Kiss1 expression was mainly found in the hypothalamus, with numerous Kiss1-expressing neurons being present in the tuberal (Figure $2 \mathrm{~A}-\mathrm{B}^{\prime}$ ) and mamillary (Figure 2A,C, $\mathrm{C}^{\prime}$ ) regions of the hypothalamus. Interestingly, we also observed the presence of a few Kiss 1 expressing cells in the paratubercular (posterior tubercle) nucleus (Figure 2A,C, $\mathrm{C}^{\prime}$ ) of the diencephalon, which is located dorsally and caudally to the hypothalamus (in the basal part of prosomeres 2 and 3).

\section{A}

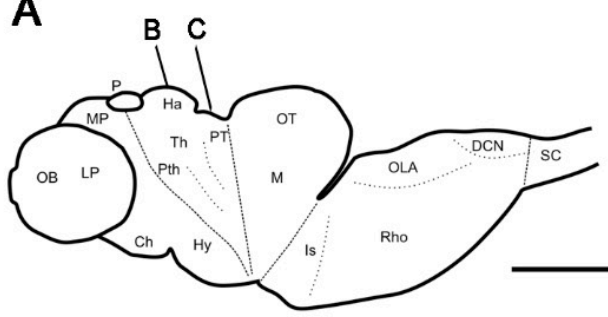

B

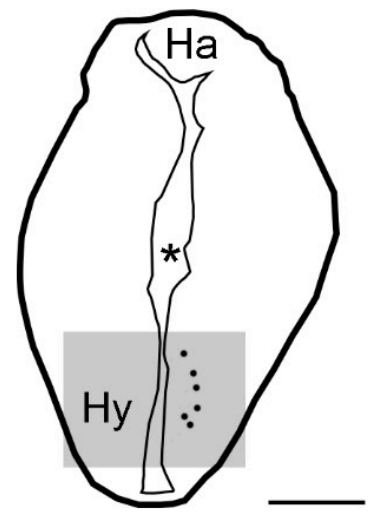

B'

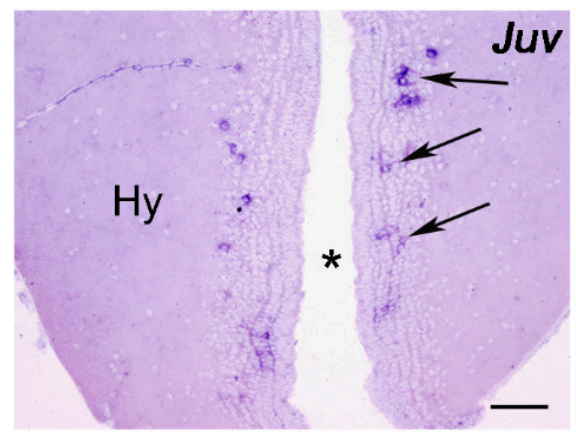

Figure 2. Cont. 

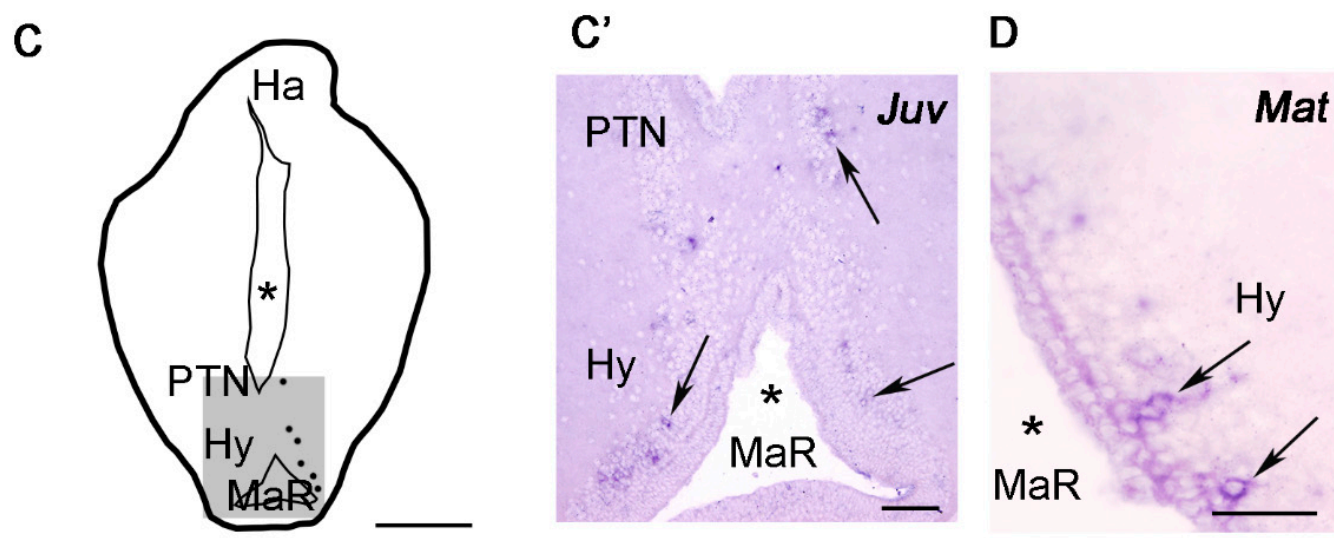

Figure 2. Schematic drawings of sections of the sea lamprey brain showing the distribution of cells expressing Kiss1 (A,B,C) and photomicrographs of in situ hybridized transverse sections showing the expression of the Kiss 1 mRNA in the brain of juvenile $\left(\mathbf{B}^{\prime}, \mathbf{C}^{\prime}\right)$ and mature (D) sea lampreys. (A): Figurine representing a lateral view of the brain. The planes of the transverse sections in $B$ and $C$ are indicated. $(B, C)$ : Cells are represented as dots on the right side of the sections. Anatomical regions are presented on the left side. $\left(\mathbf{B}^{\prime}, \mathbf{C}^{\prime}\right)$ : Photomicrographs of transverse sections of the brain of post-metamorphic juvenile (Juv) sea lampreys. (D): Photomicrograph of a transverse section of the brain of a mature (Mat) upstream migrating adult sea lamprey. Asterisks indicate the ventricle. The arrows indicate Kiss 1 expressing cells. The approximate regions of photomicrographs are represented with shadow squares in the transverse schematic drawings. Scale bars: $\mathrm{A}, \mathrm{B}$ and $\mathrm{C} 1 \mathrm{~mm}$; $\mathrm{B}^{\prime}, \mathrm{C}^{\prime}$ and D $100 \mu \mathrm{m}$. Abbreviations: Ch, optic chiasm; DCN, dorsal column nucleus; Ha, habenula; Hy, hypothalamus; Is, Isthmus; LP, lateral pallium; M, mesencephalon; MaR, mamillary recess; MP, medial pallium; OB, olfactory bulbs; OLA, octavolateralis area; OT, optic tectum; P, pineal organ; PT, pretectum; Pth, prethalamus (ventral thalamus); PTN, posterior tubercle nucleus (paratubercular nucleus); Rho, rhombencephalon; SC, spinal cord; Th thalamus (dorsal thalamus).

\section{Discussion}

In 2009, Felip et al. identified two different Kiss precursors in P. marinus [5]. Based on an unrooted phylogeny, the same authors proposed the hypothesis that only 2 Kiss precursors clusters exist in vertebrates, the Kiss 1 and Kiss 2 clusters [5]. However, sequences of species with more than two Kiss precursors were not included in their analysis. For example, from X. tropicalis, only two of the three Kiss precursors were included in the phylogeny. Later that year, Lee et al. described the presence of three different Kiss precursors in X. tropicalis [4]. Based on alignments of the mature peptides derived from the three X. tropicalis precursors, Lee et al. proposed that the third Kiss precursor from $X$. tropicalis was a duplication of the Kiss 1 precursor and named it Kiss $1 b$. However, they did not perform a phylogeny to confirm this hypothesis [4]. Here, in our phylogeny we included the sequences of a third Kiss precursor from X. tropicalis and L. oculatus and generated a rooted tree. Importantly, the node supporting the two branches of Kiss1 and Kiss 2 precursors is supported by a low branch support. It is not uncommon to obtain low support values in neuropeptide phylogenies. This is due to the short sequences of neuropeptide precursors and because neuropeptides evolve at non-homogeneous rates at different regions of the peptides [16]. For example, the regions encoding the mature peptides, the signal peptide and cleavage sites evolve under strong pressures of selection, while the rest of the precursor is highly evolvable [16]. Thus, to further test the relationship of Kiss precursors, a CLANS analysis was also performed. This analysis produced a very similar result to the one observed in the phylogeny with two main clusters, one corresponding to the Kiss 1 and the second one corresponding to the Kiss 2 precursors. Together, our results confirm the hypothesis from previous studies. First, there are only two clades of Kiss precursors, the Kiss 1 and Kiss 2 clades, and P. marinus has a precursor in each branch of the phylogeny or in each cluster of the CLANS analysis. Second, the precursors from X. tropicalis and L. oculatus are the product of a recent duplication. Our 
phylogenetic and cluster-based analyses indicate that the duplication of the ancestral Kiss precursor occurred before the separation of jawless and jawed vertebrates.

This is the first study to report the expression of the Kiss 1 gene in the brain of any jawless vertebrate. Our results indicate that Kiss hypothalamic expression is an ancestral character of all vertebrates since Kiss1 or Kiss2 genes are also expressed in the hypothalamus of different jawed fish (medaka: [17-19]; zebrafish: [18-20]; striped bass: [21]; European sea bass: [22,23]), reptiles (Chinese alligator: [24]), amphibia (Western clawed frog: [4]) or mammals (mouse: [25]). Our results revealing hypothalamic expression also suggest that Kiss1 could play a role in the regulation of the release of GnRH (the three lamprey GnRHs are expressed in the hypothalamus of both post-metamorphic juveniles and upstream migrating adults [26]) and pituitary glycoprotein hormones [7] in lampreys as in other vertebrates. Expression of Kiss1 in post-metamorphic juveniles and in upstream migrating adults suggests a relationship with key events in sexual maturation/breeding. Functional work should attempt to decipher the role of Kiss 1 peptides in the hypothalamic-pituitary system of lampreys and confirm its possible role in the regulation of GnRH release.

Our in situ hybridization analyses also revealed the expression of Kiss 1 transcripts in a few cells of the paratubercular (posterior tubercle) nucleus of the diencephalon. As far as we are aware, this is the first description of the presence of Kiss 1 neurons in this region in any vertebrate, although expression of Kiss 2 has been also reported in the zebrafish posterior tuberculum $[9,20,27]$. Despite its diencephalic location, it has been suggested that this nucleus is homologous of the substantia nigra/ventral tegmental area of mammals [28] since it contains a cluster of dopaminergic cells that projects to the striatum [26,29]. Tract-tracing studies in lampreys have also revealed projections from posterior tubercle dopaminergic cells to the optic tectum [29], rhombencephalon [30] and rostral spinal cord [31,32]. Future studies should try to determine whether dopaminergic cells of this region also express Kiss1 (as it happens with dopaminergic cells in the rostral periventricular area of the third ventricle in mice [25]) and the possible role of Kiss1 mature peptides in striatal, tectal, rhombencephalic and/or spinal cord circuits in lampreys.

We could not detect expression of Kiss2 transcripts in the juvenile or adult lamprey brain. This negative result could reflect a true lack of Kiss2 expression or could be related to insufficient sensitivity of the in situ hybridization protocol. Unfortunately, with our current data we cannot differentiate between these two scenarios. The detection of the Kiss 2 cDNA by RT-PCR from larval central nervous system samples suggests the possibility that Kiss 2 could also be expressed in the adult central nervous system but at very low levels, impeding its detection by conventional in situ hybridization (which is less sensitive than RT-PCR methods). The use of other histological or biochemical methods in the future might help in determining whether Kiss 2 is expressed in the sea lamprey brain.

\section{Conclusions}

In conclusion, the expression of Kiss genes in the hypothalamus appears to be an ancestral character for all vertebrates. Interestingly, in lampreys, Kiss 1 is also expressed in the paratubercular nucleus, which reveals an important difference in the organization of the kisspeptinergic system in comparison to mammalian species.

Supplementary Materials: The following are available online at https:/ / www.mdpi.com/article/10 $.3390 /$ life11111174/s1. Supplementary Figure S1: Cluster-based analysis of the relationships of Kiss precursors in selected species. Nodes correspond to the precursors and are color-coded according to the key. Supplementary Figure S2: Figurine representing a lateral view of the sea lamprey brain (A) and photomicrographs of in situ hybridized transverse sections showing the lack of positive signal of the Kiss 1 sense probe (negative control; B) and the lack of detectable expression of the Kiss 2 mRNA using the Kiss 2 anti-sense riboprobe in the brain of juvenile (Juv) sea lampreys (C). The planes of the transverse sections in B and C are indicated in A. Scale bars: A $1 \mathrm{~mm}, \mathrm{~B}$ and C $200 \mu \mathrm{m}$. Abbreviations: Ch, optic chiasm; DCN, dorsal column nucleus; Ha, habenula; Hy, hypothalamus; Is, Isthmus; LP, lateral pallium; M, mesencephalon; MaR, mamillary recess; MP, medial pallium; OB, olfactory bulbs; OLA, octavolateralis area; OT, optic tectum; P, pineal organ; PT, pretectum; Pth, prethalamus (ventral 
thalamus); PTN, posterior tubercle nucleus (paratubercular nucleus); Rho, rhombencephalon; SC, spinal cord; Th thalamus (dorsal thalamus). Supplementary File S1: Kiss1 alignments. Supplementary File S2: Kiss2 alignments. Supplementary File S3: Fasta file with the sequences used for the tree construction. Supplementary File S4: Nhx file with raw phylogenetic tree data.

Author Contributions: Conceptualization, A.B.-I.; methodology D.S.-C., L.A.Y.-G. and A.D.; formal analysis, D.S.-C., L.A.Y.-G., A.D., M.C.R. and A.B.-I.; writing-original draft preparation, L.A.Y.-G. and A.B.-I.; writing-review and editing, D.S.-C., L.A.Y.-G., M.C.R. and A.B.-I.; funding acquisition, A.B.-I. All authors have read and agreed to the published version of the manuscript.

Funding: This research was funded by the Ministerio de Ciencia e Innovación-Agencia Estatal de Investigación to A.B.-I. (Grant number: PID2020-115121GB-I00), the Xunta de Galicia (Grant number: ED431C 2021/18) and the European Molecular Biology Organization (EMBO) that granted a long-term EMBO fellowship to D.S.-C. (ALTF 62-2021).

Institutional Review Board Statement: All animal experiments were approved by the Bioethics Committee at the University of Santiago de Compostela and the Consellería do Medio Rural of the Xunta de Galicia (Ref. 15012/2020/011) and were performed in accordance with European Union and Spanish guidelines on animal care and experimentation.

Data Availability Statement: Data is contained within the article, and materials can be requested from the authors upon reasonable request.

Acknowledgments: We would like to thank the members of the biological station of Ximonde for help capturing the sea lampreys.

Conflicts of Interest: The authors declare no conflict of interest.

\section{References}

1. Osugi, T.; Son, Y.L.; Ubuka, T.; Satake, H.; Tsutsui, K. RFamide peptides in agnathans and basal chordates. Gen. Comp. Endocrinol. 2016, 227, 94-100. [CrossRef] [PubMed]

2. Ohtaki, T.; Shintani, Y.; Honda, S.; Matsumoto, H.; Hori, A.; Kanehashi, K.; Terao, Y.; Kumano, S.; Takatsu, Y.; Masuda, Y.; et al. Metastasis suppressor gene KiSS-1 encodes peptide ligand of a G-protein-coupled receptor. Nat. Cell Biol. 2001, 411, 613-617. [CrossRef] [PubMed]

3. Pasquier, J.; Lafont, A.-G.; Rousseau, K.; Quérat, B.; Chemineau, P.; Dufour, S. Looking for the bird Kiss: Evolutionary scenario in sauropsids. BMC Evol. Biol. 2014, 14, 30. [CrossRef]

4. Lee, Y.R.; Tsunekawa, K.; Moon, M.J.; Um, H.N.; Hwang, J.-I.; Osugi, T.; Otaki, N.; Sunakawa, Y.; Kim, K.; Vaudry, H.; et al. Molecular Evolution of Multiple Forms of Kisspeptins and GPR54 Receptors in Vertebrates. Endocrinology 2009, 150, 2837-2846. [CrossRef]

5. Felip, A.; Zanuy, S.; Pineda, R.; Pinilla, L.; Carrillo, M.; Tena-Sempere, M.; Gómez, A. Evidence for two distinct KiSS genes in non-placental vertebrates that encode kisspeptins with different gonadotropin-releasing activities in fish and mammals. Mol. Cell. Endocrinol. 2009, 312, 61-71. [CrossRef]

6. Roa, J.; Castellano, J.M.; Navarro, V.; Handelsman, D.; Pinilla, L.; Tena-Sempere, M. Kisspeptins and the control of gonadotropin secretion in male and female rodents. Peptides 2009, 30, 57-66. [CrossRef]

7. Sower, S.A. Landmark discoveries in elucidating the origins of the hypothalamic-pituitary system from the perspective of a basal vertebrate, sea lamprey. Gen. Comp. Endocrinol. 2018, 264, 3-15. [CrossRef]

8. Pasquier, J.; Lafont, A.-G.; Leprince, J.; Vaudry, H.; Rousseau, K.; Dufour, S. First evidence for a direct inhibitory effect of kisspeptins on LH expression in the eel, Anguilla anguilla. Gen. Comp. Endocrinol. 2011, 173, 216-225. [CrossRef]

9. Capella-Gutierrez, S.; Silla-Martinez, J.M.; Gabaldon, T. trimAl: A tool for automated alignment trimming in large-scale phylogenetic analyses. Bioinformatics 2009, 25, 1972-1973. [CrossRef]

10. Lemoine, F.; Correia, D.; Lefort, V.; Doppelt-Azeroual, O.; Mareuil, F.; Cohen-Boulakia, S.; Gascuel, O. NGPhylogeny.fr: New generation phylogenetic services for non-specialists. Nucleic Acids Res. 2019, 47, W260-W265. [CrossRef]

11. Frickey, T.; Lupas, A. CLANS: A Java application for visualizing protein families based on pairwise similarity. Bioinformatics 2004, 20, 3702-3704. [CrossRef]

12. Yun, S.; Furlong, M.; Sim, M.; Cho, M.; Park, S.; Cho, E.B.; Reyes-Alcaraz, A.; Hwang, J.-I.; Kim, J.; Seong, J.Y. Prevertebrate Local Gene Duplication Facilitated Expansion of the Neuropeptide GPCR Superfamily. Mol. Biol. Evol. 2015, 32, 2803-2817. [CrossRef] [PubMed]

13. Sobrido-Cameán, D.; Guerra, L.A.Y.; Lamanna, F.; Conde-Fernández, C.; Kaessmann, H.; Elphick, M.R.; Anadón, R.; Rodicio, M.C.; Barreiro-Iglesias, A. Galanin in an Agnathan: Precursor Identification and Localisation of Expression in the Brain of the Sea Lamprey Petromyzon marinus. Front. Neuroanat. 2019, 13, 83. [CrossRef] 
14. Sobrido-Cameán, D.; Yáñez-Guerra, L.A.; Robledo, D.; López-Varela, E.; Rodicio, M.C.; Elphick, M.R.; Anadón, R.; BarreiroIglesias, A. Cholecystokinin in the central nervous system of the sea lamprey Petromyzon marinus: Precursor identification and neuroanatomical relationships with other neuronal signalling systems. Anat. Embryol. 2020, 225, 249-284. [CrossRef]

15. Sobrido-Cameán, D.; Yáñez-Guerra, L.A.; Deber, A.; Freire-Delgado, M.; Cacheiro-Vázquez, R.; Rodicio, M.C.; Tostivint, H.; Anadón, R.; Barreiro-Iglesias, A. Differential expression of somatostatin genes in the central nervous system of the sea lamprey. Anat. Embryol. 2021, 226, 1031-1052. [CrossRef]

16. Foster, S.R.; Hauser, A.S.; Vedel, L.; Strachan, R.T.; Huang, X.-P.; Gavin, A.C.; Shah, S.D.; Nayak, A.P.; Haugaard-Kedström, L.; Penn, R.B.; et al. Discovery of Human Signaling Systems: Pairing Peptides to G Protein-Coupled Receptors. Cell 2019, 179, 895-908.e21. [CrossRef]

17. Kanda, S.; Akazome, Y.; Matsunaga, T.; Yamamoto, N.; Yamada, S.; Tsukamura, H.; Maeda, K.-I.; Oka, Y. Identification of KiSS-1 Product Kisspeptin and Steroid-Sensitive Sexually Dimorphic Kisspeptin Neurons in Medaka (Oryzias latipes). Endocrinology 2008, 149, 2467-2476. [CrossRef]

18. Kitahashi, T.; Ogawa, S.; Parhar, I.S. Cloning and Expression of kiss2 in the Zebrafish and Medaka. Endocrinology 2009, 150, 821-831. [CrossRef]

19. Mitani, Y.; Kanda, S.; Akazome, Y.; Zempo, B.; Oka, Y. Hypothalamic Kiss1 but Not Kiss2 Neurons Are Involved in Estrogen Feedback in Medaka (Oryzias latipes). Endocrinology 2010, 151, 1751-1759. [CrossRef]

20. Servili, A.; Le Page, Y.; Leprince, J.; Caraty, A.; Escobar, S.; Parhar, I.S.; Seong, J.Y.; Vaudry, H.; Kah, O. Organization of Two Independent Kisspeptin Systems Derived from Evolutionary-Ancient Kiss Genes in the Brain of Zebrafish. Endocrinology 2011, 152, 1527-1540. [CrossRef]

21. Zmora, N.; Stubblefield, J.; Zulperi, Z.; Biran, J.; Levavi-Sivan, B.; Muñoz-Cueto, J.A.; Zohar, Y. Differential and Gonad StageDependent Roles of Kisspeptin1 and Kisspeptin2 in Reproduction in the Modern Teleosts, Morone Species1. Biol. Reprod. 2012, 86, 177. [CrossRef]

22. Escobar, S.; Felip, A.; Gueguen, M.-M.; Zanuy, S.; Carrillo, M.; Kah, O.; Servili, A. Expression of kisspeptins in the brain and pituitary of the european sea bass (Dicentrarchus labrax). J. Comp. Neurol. 2013, 521, 933-948. [CrossRef]

23. Escobar, S.; Servili, A.; Espigares, F.; Gueguen, M.-M.; Brocal, I.; Felip, A.; Gómez, A.; Carrillo, M.; Zanuy, S.; Kah, O. Expression of Kisspeptins and Kiss Receptors Suggests a Large Range of Functions for Kisspeptin Systems in the Brain of the European Sea Bass. PLoS ONE 2013, 8, e70177. [CrossRef]

24. Zhang, R.; Nie, H.; Duan, S.; Yan, P.; Izaz, A.; Wang, R.; Zhou, Y.; Wu, X. Cloning, characterisation and expression profile of kisspeptin1 and the kisspeptin1 receptor in the hypothalamic-pituitary-ovarian axis of Chinese alligator Alligator sinensis during the reproductive cycle. Reprod. Fertil. Dev. 2020, 32, 792-804. [CrossRef]

25. Clarkson, J.; Herbison, A.E. Postnatal Development of Kisspeptin Neurons in Mouse Hypothalamus; Sexual Dimorphism and Projections to Gonadotropin-Releasing Hormone Neurons. Endocrinology 2006, 147, 5817-5825. [CrossRef]

26. Van Gulick, E.R.; Marquis, T.J.; Sower, S.A. Co-localization of three gonadotropin-releasing hormone transcripts in larval, parasitic, and adult sea lamprey brains. Gen. Comp. Endocrinol. 2018, 264, 84-93. [CrossRef]

27. Song, Y.; Duan, X.; Chen, J.; Huang, W.; Zhu, Z.; Hu, W. The Distribution of Kisspeptin (Kiss)1- and Kiss2-Positive Neurones and Their Connections with Gonadotrophin-Releasing Hormone-3 Neurones in the Zebrafish Brain. J. Neuroendocr. 2015, $27,198-211$. [CrossRef]

28. Pombal, M.A.; El Manira, A.; Grillner, S. Afferents of the lamprey striatum with special reference to the dopaminergic system: A combined tracing and immunohistochemical study. J. Comp. Neurol. 1997, 386, 71-91. [CrossRef]

29. Pérez-Fernández, J.; Stephenson-Jones, M.; Suryanarayana, S.M.; Robertson, B.; Grillner, S. Evolutionarily conserved organization of the dopaminergic system in lamprey: SNc/VTA afferent and efferent connectivity and D2 receptor expression. J. Comp. Neurol. 2014, 522, 3775-3794. [CrossRef]

30. von Twickel, A.; Kowatschew, D.; Saltürk, M.; Schauer, M.; Robertson, B.; Korsching, S.; Walkowiak, W.; Grillner, S.; PérezFernández, J. Individual Dopaminergic Neurons of Lamprey SNc/VTA Project to Both the Striatum and Optic Tectum but Restrict Co-release of Glutamate to Striatum Only. Curr. Biol. 2019, 29, 677-685. [CrossRef]

31. Ryczko, D.; Grätsch, S.; Alpert, M.H.; Cone, J.J.; Kasemir, J.; Ruthe, A.; Beauséjour, P.-A.; Auclair, F.; Roitman, M.F.; Alford, S.; et al. Descending Dopaminergic Inputs to Reticulospinal Neurons Promote Locomotor Movements. J. Neurosci. 2020, 40, 8478-8490. [CrossRef]

32. Barreiro-Iglesias, A.; Villar-Cerviño, V.; Anadón, R.; Rodicio, M.C. Descending brain-spinal cord projections in a primitive vertebrate, the lamprey: Cerebrospinal fluid-contacting and dopaminergic neurons. J. Comp. Neurol. 2008, 511, 711-723. [CrossRef] 